\title{
The role of drugs in the control of parasitic nematode infections: must we do without?
}

\author{
M. H. ROOS \\ Institute for Animal Science and Health (ID-DLO), Department of Molecular Recognition, P.O. Box, 65, 8200 AB, \\ Lelystad, The Netherlands
}

\begin{abstract}
S U M M A R Y
Parasitic helminths (worms) cause serious infectious diseases in humans and domestic animals. Control of these infections relies mostly on chemotherapeutics (the anthelmintics), but resistance has developed against most of these broad-spectrum drugs in many parasite species. These resistant parasites are being used to elucidate the molecular mechanisms of drug resistance and drug action. This has led to the development of sensitive assays to detect resistant parasites, but this has not delayed the emergence of additional drug resistant parasite populations. Therefore, as development of new drugs by pharmaceutical companies is slow, we may have to be prepared for a time when broad-spectrum drugs are no longer effective, especially against worms of sheep.
\end{abstract}

Key words: drug resistance, genetic resistance, parasite, nematode, anthelmintics.

\section{INTRODUCTION}

Nematode parasites cause serious morbidity and mortality in humans and farm animals. Therefore much research has been carried out on ways to control these parasites, as eradication seems impossible. Several methods of control of these parasites have been investigated but the most frequently used one is chemotherapy, especially since broad spectrum drugs were introduced to the market. The drugs used have caused hardly any drug resistance in humans and cattle, but in sheep the abundant use of anthelmintics has caused the selection of drug resistant populations (Jackson, 1993; Prichard, 1994; Waller, 1994). Development of in vivo and in vitro methods to measure the progress of the selection for anthelmintic resistance has apparently not resulted in the delay of the appearance of resistance (Prichard, 1994; Coles \& Klei, 1995; Roos, Kwa \& Grant, 1995; Waller et al. 1996). The main reason may be the lack of information made available to the farmer, a situation that is likely to remain the same in the near future (Dangolla et al. 1996). As the development of new drugs is slow we may have to be prepared for a time without broadspectrum drugs against sleep nematode parasites.

All means that are used to reduce the workload of sheep diminish the selection pressure for natural genetic resistance to these parasites. It is well known that sheep breeds that are never treated by drugs have a much higher level of natural resistance to parasites than the breeds that are selected for high production and that are regularly treated (Barger,
1989; Baker, 1995). This means that, when drugs fail, farmers are in a worse situation compared to before widespread drug use. However, within these latter breeds there is much difference between the sheep with regard to the worm load and this is genetically inherited (Watson, Hosking \& Hurford, 1992; Barger, 1993; Stear \& Murray, 1994). Therefore the gene(s) involved in the genetic resistance are not lost from these sheep populations. It thus has been possible to start breeding for genetic resistance in the high production sheep breeds without production loss (Barger, 1993). If these methods are implemented by farmers they will reduce the need for drugs, delay drug resistance and produces less drug residue in milk and less environmental pollution.

The development of genetic polymorphic markers, microsatellite or others, for sheep and the mapping of those on the sheep genome will enable us to identify the markers and genes that are important for genetic resistance (Broad \& Hill, 1994; Stear et al. 1996). This will then be an easy tool to use in the selection of the rams needed for breeding to increase genetic resistance in the flock.

Although the breeding of genetically resistant sheep will not eliminate the parasites but is likely to diminish the incidence in sheep to $10-20 \%$ of what it is now, it is a feasible method with the potential advantage that is relatively available to all farmers (Barger, 1993). It will greatly reduce the workload of sheep and contamination of the fields. Together with other control measures (see below), it should be possible to reduce or replace anthelmintic use. 
CONTROL OF HELMINTH INFECTIONS

To prevent human infections, non-invasive and sanity measures, like intermediate host control, improvements in housing, sewage disposal and water supply are extremely important (Gutteridge, 1989). This is illustrated by the fact that in most 'developed countries' the level of infection of helminths in man is very low without widespread chemotherapy or vaccination. In contrast, the level of infections is high in 'developing countries', where the implementation of hygiene is still low due to financial and social problems (Guyatt \& Evans, 1992). In farm animals, where infection rates can be high due to intensive farming methods, non-invasive methods have also proved to be useful. Reduction of infection by manipulation of the grazing environment limits host-parasite contact, but most farmers are not able to implement these measures (Jackson, 1993). Breeding for genetic resistance of the host to the parasite has been shown to be possible with several host species, like cattle and sheep, but has not yet been used much by farmers (Kloosterman, Parmentier \& Ploeger, 1992; Watson et al. 1992). This is probably due to the fact that in order to select bulls or rams for breeding, in the absence of molecular markers to characterize animals, it would be necessary to infect the animals with worms to determine their degree of resistance.

Invasive control methods are chemotherapy and vaccination. Extensive research has shown that there is still a long way to go before effective vaccines against human and animal helminths can be developed. The major problems to be overcome are the manipulation by the parasite of the host immune system and our still primitive knowledge of the basic mechanisms of host-parasite interactions (Smith, 1992; Jasmer \& McGuire, 1996). Anthelmintic drugs are the most widely used means to control helminth infections. They have so far failed to eradicate any parasite species in specific geographical regions because of the adaptability of the parasites when under intensive selection pressure (Jackson, 1993; Pritchard, 1994; Waller, 1994). Anthelmintics are available now for the treatment of the major helminth infections of humans and domestic animals (Gutteridge, 1989). Due to costs and logistics, however, these drugs are not readily available to many people and farm animals in developing countries. In contrast, they are being used extensively and successfully in veterinary medicine in developed countries. Unfortunately, irreversible resistance develops in helminths, usually within 5 years of introduction of the drug. Drug resistance of parasitic helminths is becoming a serious problem in veterinary medicine, especially in sheep husbandry. Sheep farmers cannot farm profitably without extensive control of helminth parasites. As resistance has been found now against all major groups of broad-spectrum drugs, management of chemotherapy, to delay or prevent resistance, is imperative in this branch of agriculture (Jackson, 1993; Waller et al. 1996).

Biological control methods, through the use of nematophagous fungi, seem to be feasible for some nematode parasites. The disadvantage is that the adult parasites are not killed and only the eggs are destroyed by the fungi. Furthermore, the host has to be fed the fungi daily. It may be a useful method, when integrated with other control strategies (Ǵronvold et al. 1993).

Methods on how to control parasites and delay drug resistance have been investigated by mathematical modelling. Although these models are based on a scant knowledge of parasite biology and host-parasite interactions, they generate protocols for experiments in the field. They suggest that to delay anthelmintic resistance, administering drugs from different groups simultaneously (Smith, 1990; Barnes, Bobson \& Barger, 1995) would be better than rotating drugs on an annual basis. Another method would be treating only $80-90 \%$ of the lambs with drugs (Barnes et al. 1995). Field experiments are needed, however, to confirm these approaches.

\section{ANTHELMINTIC DRUGS}

Since broad-spectrum drugs (that is, drugs that are active against several unrelated species of parasites) are available, they are the drugs of choice and used most widely. There are only three groups of broadspectrum drugs available, each with a different mode of action (see Martin, Robertson \& Bjorn, this volume). These drugs have the common feature that they kill the parasites and do not harm the host, when the prescribed concentrations are used (Barragry, 1984a, b).

The first broad-spectrum group of drugs were the benzimidazole (BZ) derivatives, initially marketed in the 1960s. Different pharmaceutical/agrochemical companies made their own derivatives from the same core structure. The drugs all show cross-resistance. Extensive studies indicated that BZ were antimitotics that disrupted the microtubules and mitotic spindles of the parasites, but not those of the host. The reason for this differential action is still not entirely clear (Lacey, 1988; Martin et al., this volume).

The second group of broad-spectrum drugs became available in the early 1970s and comprises the group of imidothiazoles, including levamisole and tetramisole. The pyrimidines pyrantel and morantel are classified in this group because there is cross-resistance with the imidothiazoles (Prichard, 1994). The drugs cause spastic paralysis of the parasite, which may not be killed immediately but is expelled because of the paralysis. The exact mechanism of action is not known, although some recent 
data indicate that in the free-living nematode Caenorhabditis elegans levamisole binds to a nicotinic acetylcholine receptor (Lewis \& Berberich, 1992; Martin et al., this volume).

The third group of broad-spectrum drugs, the avermectins, became available in the 1980s (Campbell, 1993). These drugs are extremely effective against nematodes and insects (Shoop, 1993). The site of action of one of them, ivermectin, has been studied. Results from crayfish and the nematode Ascaris suum suggested an interaction with receptors at chloride channels (Holden-Dye \& Walker, 1990). Subsequently, genes encoding ivermectin-sensitive glutamate-gated chloride channel subunits were isolated from the nematode C.elegans (Arena et al. 1995). At least one of these genes is expressed in the pharyngeal muscle cells and this is consistent with the hypothesis that ivermectin inhibits the pharyngeal pumping of nematodes (Geary et al. 1993). In addition, binding of ivermectin to membrane transporters like P-glycoprotein has been reported (Schinkel et al. 1994). The genetics of ivermectin resistance seems to be simple: it is probably inherited as a single dominant allele. This was suggested for the nematode Haemonchus contortus (LeJambre et al. 1995; LeJambre, personal communication); using 2 different susceptible and 2 different resistant populations, it appeared that it was a classical example of inheritance of resistance as one dominant allele.

The use of narrow-spectrum drugs diminished in veterinary medicine after the broad-spectrum drugs became available. However, against human schistosomiasis the specific drug praziquantel is used with much success (Day, Bennett \& Pax, 1992). The precise mechanism of action is unclear (Martin et al. this volume), but it has been shown that the immune system of the host is needed, in addition to the drug, to kill the worms. Another antischistosomal drug, hycanthone, is also effective against some other species of worms that reside in or feed from the host blood (Cioli, Pica-Mattoccia \& Archer, 1993).

DEVELOPMENT OF DRUG RESISTANCE

The selection pressure of drugs to eradicate worms has inevitably selected for drug-resistant parasites. These drug-resistant parasites, however, are a key to the elucidation of the molecular mechanism of action of the drugs. Resistance has been reported against the three groups of broad-spectrum drugs and on some farms the parasites are resistant against several groups of drugs. Assays to monitor the onset of selection by each of the three drug groups are needed, because timely rotation or mixtures of drugs may delay and even select against resistance (Jackson, 1993; Roush, 1993). At the moment, however, the assays available only detect resistance when about $25 \%$ of the population is already resistant (Jackson, 1993). As resistance is often caused by one gene that is recessive (Roush, 1993), this means that the gene frequency of the resistant gene is already $0 \cdot 5$ and reversion at that time is very difficult. Therefore, much more sensitive assays are needed to investigate the dynamics of resistance development. However, influencing farmers' habits to reduce or change the use of anthelmintics may be difficult (Dangolla et al. 1996).

In human parasites, no resistance has been convincingly shown yet against the three groups of broad-spectrum drugs. This is probably due to a far less frequent and better controlled use than in veterinary medicine. A report from the WHO has suggested, however, that there is resistance against praziquantel in schistosomes (TDR News, 1992). Resistance of schistosomes to hycanthone is well documented and is a very nice illustration of the fact that resistant populations can reveal the mechanism of action of drugs. A parasite enzyme is able to convert hycanthone to an unstable ester form that then alkylates DNA and kills the parasite. Resistant worms lack this enzyme activity (Cioli et al. 1993).

However, research into drug resistance and the mechanism of anthelmintic action is not always that straightforward. To investigate ivermectin resistance in parasitic nematodes, one approach that was used involved the study of resistant strains of the freeliving nematode C.elegans, which is susceptible to the drug (Schaeffer \& Haines, 1989). So far mutations in more than 35 independent genes that are responsible for various levels of resistance have been identified (C. Johnson, personal communication). Comparison with the development of drug resistance in insects predicts that only a few of these mutations are involved in the resistance mechanisms found in the field (Roush, 1993). However, the mechanism of the ivermectin resistance is still unknown, as the membranes of ivermectin-resistant and -susceptible larvae of $H$. contortus harbour similar numbers of ivermectin-binding sites with the same affinity characteristics (Rohrer et al. 1994). Our own results indicate that a $\mathrm{P}$-glycoprotein gene, which we cloned from $H$. contortus, is not involved in ivermectin resistance (M. S. G. Kwa \& M. H. Roos, unpublished).

Research into the mode of resistance to levamisole has not yet elucidated the mechanism(s). Characterization of the alpha chains of the nicotinic acetylcholine receptor of two nematode species, $T$. colubriformis and $H$. contortus, did not reveal any difference in amino acid sequence between susceptible and resistant worms (Wiley et al., 1996, Martin et al. this volume, Hoekstra et al. 1997).

We have been investigating the mechanism of benzimidazole resistance in the sheep nematode parasite $H$. contortus. The results, which indicate the mechanism of drug action, are described below. 
MOLECULAR MECHANISMS OF BENZIMIDAZOLE RESISTANCE IN THE SHEEP NEMATODE

H. CONTORTUS

Early studies on the mechanism of BZ resistance indicated the presence in resistant worms of microtubules that could not be disrupted at concentrations of $\mathrm{BZ}$ that destroyed them in susceptible worms (reviewed by Lacey, 1988). In vitro binding assays, using partly purified tubulin preparations from resistant and susceptible parasites, with tritiated BZ indicated a lower binding of the drug in resistant populations. This argues against gene amplification of tubulins as the mechanism of resistance, because in that case a higher binding of the drug in resistant worms would have been found. When host tubulin was used in these assays, it had the same low binding as that from resistant worms (Lacey, 1988).

Extensive studies on the mechanism of BZ resistance has been carried out in fungi, as BZ are also fungicides (Davidse, 1986). In vitro mutagenesis of several different species and site-directed mutagenesis indicated that one point mutation in the $\beta$ tubulin gene, that led to an amino acid change, was enough to cause resistance (Thomas, Neff \& Botstein, 1985; Jung, Wilder \& Oakley, 1992; Li et al. 1996). These mutations were not clustered but spread out over the whole length of the gene. Interestingly some recent resistant isolates from the field of the yeast Venturia inaequalis showed only a selected number of those in vitro generated mutations, notably changes at amino acids 198 and 200 (Koenraadt, Sommerville \& Jones, 1992).

In vitro mutagenesis studies were also carried out with $C$. elegans for this anthelmintic group. The $C$. elegans genome contains at least three loci for $\beta$ tubulin, at one of which a gene is located that determines BZ susceptibility. If this gene is deleted or truncated, the worm is $\mathrm{BZ}$ resistant. Comparison of the amino acid sequences between the 3 genes indicated 6 differences between the gene conferring susceptibility (ben-1) and the 2 conferring resistance (mec-7 and tub-1) (Driscoll et al. 1989). Comparison with the mutations in $V$. inequalis indicated that 2 different mutations, one at amino acid 198 (mec-7) and one at amino acid $200(t u b-1)$, could be involved in the resistance of the 2 genes.

We started the molecular characterization of $\beta$-tubulin in benzimidazole-resistant (BZ-R) and benzimidazole-susceptible $(\mathrm{BZ}-\mathrm{S})$ populations by cloning a $\beta$-tubulin gene from a genomic library constructed from a resistant population. This gene was used as a probe on Southern blots with the DNA from several BZ-susceptible and BZ-resistant populations. An extensive polymorphism, 5-10 bands, was seen in susceptible populations, while in resistant populations usually only one band was visible. This indicated selection for this specific fragment. An in vitro selection experiment confirmed this conclusion and indicated in addition that the selected fragment was already present at a low concentration in the susceptible population that was used for the selection. The dynamics of the selection indicated that resistance was recessive (Roos, 1990; Roos et al. 1990, Roos \& Boersema, 1991). Further characterization of the apparently selected fragment by restriction mapping of the upstream and downstream regions of the gene indicated one $\beta$-tubulin gene in resistant populations. This gene was probably functional because there was transcription (Kwa et al. $1993 a$ ). Therefore we supposed that there was one locus on which a gene was located with many susceptible alleles and one, or a few, resistant ones. We called these gene products $\beta$-tubulin isotype 1 . Selection pressure with $\mathrm{BZ}$ resulted in the survival of the resistant worms that carried a specific $\beta$ tubulin isotype 1 allele (Kwa et al. 1993 b; Roos, Kwa \& Grant, 1995).

The in vitro selection experiment, in which we reached maximal resistance after 4 selection steps, indicated that after 3 selection steps there was only one $\beta$-tubulin isotype 1 gene left in the population. There was, however, a doubling of the resistance factor after the fourth selection step. By this time, Geary et al. (1992) had published several $\beta$-tubulin cDNA sequences from a susceptible population. Differences in sequences and in reactions in Southern blots indicated 2 separate loci, one of which was coding for a $\beta$-tubulin similar to the product of our isotype 1 gene. The other sequences were called isotype 2. Hybridization of a Southern blot using an isotype 2 gene as probe indicated that in the fourth selection step there was an elimination of worms carrying this gene (Kwa et al. 1993 a). Therefore 2 mechanisms of resistance were identified; at lower resistance level there was a selection for a specific isotype 1 gene, and at higher resistance levels there was a deletion of worms with isotype 2 genes.

Further analysis of isotype 1 genes by amino acid sequence comparison of 'our' resistant gene with isotype 1 sequence 8-9 from Geary et al. (1992) indicated 3 differences between the amino acid sequences, at amino acids 76, 200 and 368. We sequenced a susceptible gene also and there was only one base difference that caused the amino acid difference at 200 (Kwa, Veenstra \& Roos, 1994). The difference at amino acid 200, a Phe/Tyr transition, was exactly the same difference as was found in the resistant field isolates of $V$. inaequalis. Therefore we constructed specific sense oligonucleotides, using this mutation, that ended with a different $3^{\prime}$ nucleotide. These nucleotides were used in a PCR and we were able to discriminate between $\mathrm{BZ}-\mathrm{R}$ and BZ-S populations isolated from Europe (Kwa et al. 1994). This indicated that in $H$. contortus a mutation identical to the one in fungi could be responsible for $\mathrm{BZ}$ resistance.

To investigate further the function of the poly- 

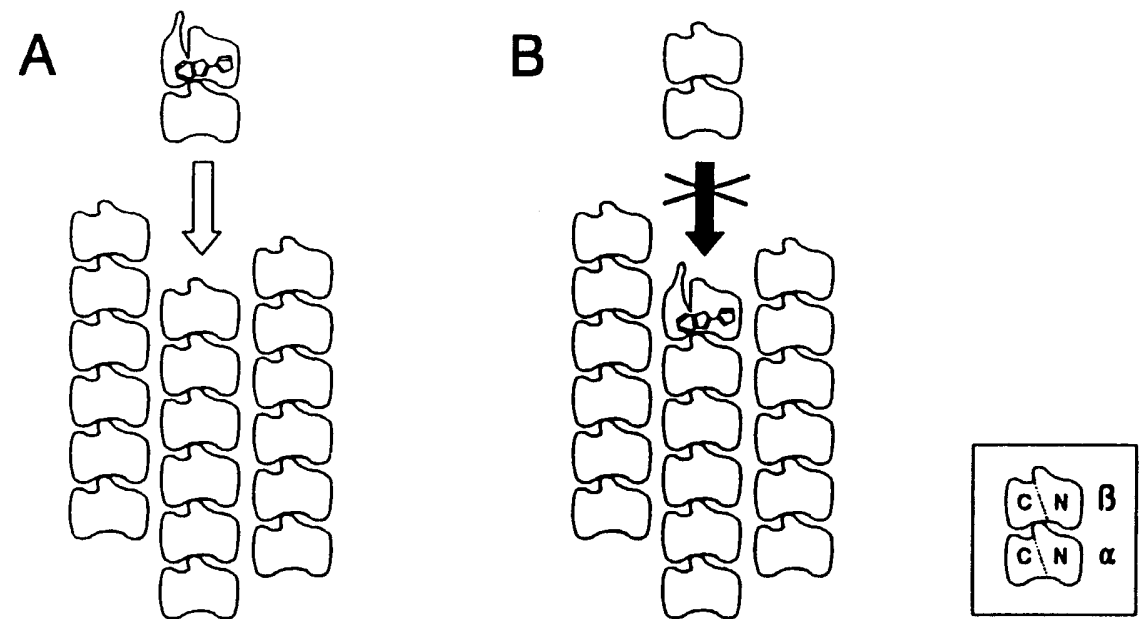

Fig. 1. A model for the mode of action of antimitotic drugs such as benzimidazoles (BZ) and colchicine. The box shows the $\alpha$-and $\beta$-subunits. Both the carboxy- $(\mathrm{C})$ and amino-(N) terminal regions are indicated. In panel A, the tubulin-BZ complex is about to be added to the growing microtubule. The $\beta$-tubulin carboxy terminus shows the unfolding region induced by the drug binding. Since the rest of the $\beta$-tubulin is unaltered, interaction with $\alpha$-tubulin and addition to the growing microtubule is still possible. However, panel B shows that once added to the microtubule the abnormally unfolded loop of $\beta$-tubulin prevents further addition of sub-units, thereby inhibiting further microtubule polymerization (Kwa, 1994, modified after Mitchison, 1993; Sackett \& Verma, 1993; Uppuluri et al. 1993).

morphism at amino acid 200, we used the free-living nematode $C$. elegans as an expression system. A BZ$\mathrm{R}$ strain, ben-1, of $C$. elegans was transformed with a $\beta$-tubulin isotype 1 gene isolated from a BZ-S $H$. contortus population. Expression of the H. contortus gene altered the phenotype of transgenic C. elegans from resistant to susceptible. Introduction of the Phe to Tyr substitution of this parasite gene at amino acid 200 by in vitro mutagenesis resulted in the loss of reverting activity (Kwa et al. 1995). This indicates that this substitution can play a direct role in determining BZ susceptibility and excludes the possibility that the Phe to Tyr substitution is simply tightly linked to some other, unknown, resistance determinant. Similarly, transformation of BZ-R C. elegans with a cloned susceptibility allele of $T$. colubriformis resulted in partial reversion in partial reversion of the resistance, whereas transformation with a resistance allele did not (W. N. Grant, personal communication).

Our recent studies, using the allele-specific PCR to detect susceptible and resistant $\beta$-tubulin alleles, indicate that susceptible isotype 1 alleles can be found only on farms that do not use benzimidazoles (M. H. Roos et al., unpublished). This fits in with our previous results on in vitro selection for BZ resistance (Roos et al. 1995). The loss of the susceptible alleles in this very early stage of the selection shows that reversion of resistance may be a remote possibility in delaying or stopping $\mathrm{BZ}$ resistance.

ROLE OF MUTATIONS IN $\beta$-TUBULIN IN BZ RESISTANCE

How the point mutations in $\beta$-tubulin affect $\mathrm{BZ}$ resistance is difficult to investigate. $\beta$-tubulin is a
GTP-binding protein and GTP is needed for assembly, with $\beta$-tubulin, of the microtubules. However, it has never been crystallized and the secondary and tertiary structures of the molecule are not known (Sternlicht, Yaffe \& Farr, 1987). The fact that $\mathrm{BZ}$ drugs are nucleotide analogues, and codon 200 is located near the nucleotide binding domain II, suggests that a slight conformational change may alter the properties of the GTP binding. Indeed, site-directed mutagenesis studies of mammalian brain $\beta$-tubulin (Farr \& Sternlicht, 1992) involving, for instance, amino acid residue 197 enhanced affinity for all nucleotides. Several studies suggest that resistance to antimitotic drugs correlates with an increase of the level of polymerized tubulin (Minotti, Barlow \& Cabral, 1991), or with enhancement of microtubule stability (Schibler \& Huang, 1991). A structural model by Mitchison (1993) predicted the localization of the exchangeable GTP-binding site at the plus end of microtubules, indicating its importance for polymerization. This is supported by recent biochemical evidence, which demonstrates that the classic antimitotic drug colchicine, binds to 2 regions in mammalian brain $\beta$-tubulin (amino acids 1-46 and 214-242) (Uppuluri et al. 1993) and thereby induces local unfolding of a small region in the carboxy-terminus around amino acid 390. This is shown diagrammatically in Fig. 1.

\section{CONCLUSIONS}

The future control of helminth parasites will depend on proper use of all possible means to eradicate them. Whichever method is used, however, if it prevents or reduces contact between parasite and host it will diminish the selection for natural 
resistance to parasites in the sheep. Unfortunately, mathematical models have not included the breeding for genetic resistance in sheep, otherwise we would know more about integrating this method with other means for control. As reversion or delay of drug resistance is not a real possibility, we have to take care that natural resistance is brought back to the original level in the sheep breeds. This will be an important contribution to controlling the worm load and can be implemented by all farmers if easy methods for typing are developed. Therefore research is needed to find the molecular markers that are linked with this resistance in all the major breeds of sheep. These markers could also be used to locate and investigate, by linkage analysis, the functional genes involved in the resistance of sheep. In the future, these genes could be used to inject sheep embryos to make transgenic resistant sheep. The advantage is that there will be no need for selecting and breeding for resistance of the different breeds. Moreover, the chances for selection of worms that can escape the genetic resistance in sheep seems remote (Woolaston, Elwin \& Barger, 1992). We have to restore the innate parasite resistance to sheep, otherwise, after breakdown of the broad-spectrum drugs, the farmers will be in a far worse situation than before these drugs became available.

\section{ACKNOWLEDGEMENTS}

I acknowledge the financial support provided by the Netherlands Royal Academy of Sciences and Arts (KNAW), the Netherlands Sciences Organization (NWO BION) and the Foundation for Technical Research (STW), through grants 429.75STW and STW UDG99.211, and the EC through grant PL920019. We thank W. van der Aar and our undergraduate students for their expert technical assistance.

\section{REFERENCES}

ARENA, J. P., LiU, K. L., PARESS, P. S., EASTER, G., FRAZIER, G., CUlLy, D. F., MROZIK, H. \& SHAEFFER, J. M. (1995).

The mechanism of action of avermectins in

Caenorhabditis elegans: correlation between activation of glutamate-sensitive chloride current, membrane binding, and biological activity. Fournal of

Parasitology 81, 286-294.

BAKER, R. L. (1995). Genetics of disease resistance in small ruminants in Africa. In: Breeding for Resistance to Infectious Diseases of Small Ruminants. (Ed. Gray, G. D., Woolaston, R. R. and Eaton, B. T.) pp. 120-138. ACIR Monograph No. 34, Canberra, Australia.

BARger, I. A. (1989). Genetic resistance of hosts and its influence on epidemiology. Veterinary Parasitology 321, 21-35.

BARGER, I. A. (1993). Control of gastrointestinal nematodes in Australia in the 21 st century. Veterinary Parasitology 26, 23-32.

BARNES, E. H., BOBSON, R. J. \& BARGER, I. A. (1995). Worm control and anthelmintic resistance: adventures with a model. Parasitology Today 11, 56-63.
BARragry, T. $(1984 a)$. Anthelmintics - a review. New Zealand Veterinary Fournal 32, 161-164.

BARRAGRY, T. $(1984 b)$. Anthelmintics - review part II. New Zealand Veterinary fournal 32, 191-199.

BROAD, T. E. \& HILL, D. F. (1994). Mapping the sheep genome: practice, progress and promise. British Veterinary fournal 150, 237-252.

CAMPBELL, W. C. (1993). Ivermectin, an antiparasitic agent. Medicinal Research Reviews 13, 61-79.

COLES, G. C. \& KLEI, T. R. (1995). Animal parasites, politics and agricultural research. Parasitology Today 11, 276-278.

CiOli, D., PICA-MATTOCCIA, L. \& ARCher, s. (1993). Drug resistance in schistosomes. Parasitology Today $\mathbf{9}$, 162-166.

DANGOLLA, A., BJORN, H., WILlEBERG, P., ROEPSTORFF, A. \& NANSEN, P. (1996). A questionnaire investigation on factors of importance for the development of anthelmintic resistance in sow herds of Denmark. Veterinary Parasitology 63, 257-271.

DAVIDSE, L. C. (1986). Benzimidazole fungicides: mechanism of action and biological impact. Annual Review of Phytopathology 24, 43-65.

DAY, T. A., BENNET, J. L. \& PAX, R. A. (1992). Praziquantel: the enigmatic antiparasitic. Parasitology Today $\mathbf{8}$, $342-344$

DRISCOLL, M., DEAN, E., REILly, E., BERGHOLZ, E. \& CHALfiE, M. (1989). Genetic and molecular analysis of a Caenorhabditis elegans $\beta$-tubulin that conveys benzimidazole sensitivity. Fournal of Cell Biology 109, 2993-3003.

FARR, G. W. \& STERNLICHT, H. (1992). Site-directed mutagenesis of the GTP-binding domain of $\beta$-tubulin. Fournal of Molecular Biology 227, 307-321.

GEARY, T. G., NUlf, S. G., FAVREAU, M. A., TANG, L., PRICHARD, R. K., HATZENBUHLER, N. T., SHEA, M. H., ALEXANDER, S. J. \& KLEIN, R. D. (1992). Three $\beta$-tubulin cDNAs from the parasitic nematode Haemonchus contortus. Molecular and Biochemical Parasitology 50, 295-306.

GEARY, T. G., SIMS, S. M., THOMAS, E. M., VANOVER, L., DAVIS, J. P., WINTERROWD, A., KLEIN, R. D., HO, N. H. F. \& THOMPSON, D. P. (1993). Haemonchus contortus : ivermectin-induced paralysis of the pharynx. Experimental Parasitology 77, 88-96.

GRONVOLD, J., WOLSTRUP, J., NANSEN, P. \& HENRIKSEN, S. A. (1993). Nematode-trapping fungi against parasitic cattle nematodes. Parasitology Today 9, 137-140.

GUtTeridge, w. E. (1989). Parasite vaccines versus antiparasite drugs: rivals or running mates? Parasitology 98, S87-S97.

GUYATT, H. L. \& EVANS, D. (1992). Economic considerations for helminth control. Parasitology Today 8, 397-402.

HOEKSTRA, R., VISSER, A., WILEy, L. J., Weiss, A. S., SANGSTER, N. C. \& ROOS, M. H. (1997). Characterization of an acetylcholine receptor gene from Haemonchus contortus in relation to levamisole resistance. Molecular and Biochemical Parasitology, in press.

HOLDEN-DYE, L. \& WALKER, R. J. (1990). Avermectin and avermectin derivatives are antagonists at the 4aminoabutyric acid (GABA) receptor on the somatic muscle cells of Ascaris; is this the site of anthelmintic action? Parasitology 101, 265-271. 
JACKSON, F. (1993). Anthelmintic resistance - the state of the play. British Veterinary Fournal 149, 123-138.

JASMER, D. P. \& MCGUiRE, T. C. (1996). Antigens with application toward immune control of blood feeding parasitic nematodes. British Veterinary Fournal 152, 251-268.

JUNG, M. K., WILDER, I. B. \& OAKLEY, B. R. (1992). Amino acid alterations in the $\operatorname{ben} A$ ( $\beta$-tubulin) gene of Aspergillus nidulans that confer benomyl resistance. Cell Motility छ Cytoskeleton 22, 170-174.

Kloosterman, A., Parmentier, H. K. \& Ploeger, H. W. (1992). Breeding cattle and sheep for resistance to gastrointestinal nematodes. Parasitology Today 8, 330-335.

KOENRAADT, H., SOMMERVille, S. C. \& JONES, A. L. (1992). Characterization of mutations in the beta-tubulin gene of benomyl-resistant field strains of Venturia inaequalis and other pathogenic fungi. Resistant Pest Management Newsletter 4, 21.

KWA, M. S. G. (1994). The molecular basis of chemotherapeutic resistance in the parasitic nematode Haemonchus contortus. Ph.D. thesis, Faculty of Veterinary Medicine, University of Utrecht.

KWA, M. S. G., KOOYMAN, F. J., BOERSEMA, J. H. \& ROOS, M. H. (1993a). Effect of selection for benzimidazole resistance in Haemonchus contortus on $\beta$-tubulin isotype 1 and isotype 2 genes. Biochemical and Biophysics Research Communications 191, 413-419.

KWA, M. S. G., veEnstra, J. G. \& RoOs, M. H. (1993b). Molecular characterization of $\beta$-tubulin genes present in benzimidazole resistant populations of Haemonchus contortus. Molecular and Biochemical Parasitology 60, 133-144.

KWA, M. S. G., VeEnstra, J. G. \& Roos, M. H. (1994). Benzimidazole resistance in Haemonchus contortus is correlated with a conserved mutation at amino acid 200 in $\beta$-tubulin isotype 1. Molecular and Biochemical Parasitology 63, 299-303.

KWA, M. S. G., VEenstra, J. G., VAN DiJK, M. \& ROOS, M. H. (1995). $\beta$-tubulin genes from the parasitic nematode Haemonchus contortus modulate drug resistance in Caenorhabditis elegans. Fournal of Molecular Biology 246, 500-510.

LACEY, E. (1988). The role of the cytoskeletal protein, tubulin, in the mode of action and mechanism of drug resistance to benzimadazoles. International Fournal for Parasitology 18, 885-936.

LE Jambre, L., Gill, J. H., Lenane, I. J. \& LaCey, E. (1995). Characterization of an Avermectin resistant strain of Australian Haemonchus contortus. International Fournal for Parasitology 25, 691-698.

LEWIS, J. A. \& BERBERICH, s. (1992). A detergentsolubilized nicotinic acetylcholine receptor of Caenorhabditis elegans. Brain Research Bulletin 29, 667-674.

Li, J., SAntosh, K., Katiyar, K. \& Edlin, D. (1996). Sitedirected mutagenesis of Saccharomyces cerevisiae btubulin: interaction between residue 167 and benzimidazole compounds. FEBS Letters 385, 7-10. minotTi, A. M., Barlow, s. B. \& Cabral, F. (1991). Resistance to antimitotic drugs in chinese hamster ovary cells correlates with changes in the level of polymerized tubulin. Fournal of Biological Chemistry 266, 3987-3994.
Mitchison, T. J. (1993). Localization of an exchangeable GTP binding site at the plus end of microtubules. Science 261, 1044-1047.

PRICHARD, R. K. (1990). Anthelmintic resistance in nematodes: extent, recent understanding and future directions for control and research. International Fournal for Parasitology 20, 515-523.

PRICHARD, R. K. (1994). Anthelmintic resistance. Veterinary Parasitology 54, 259-268.

ROHRER, S. P., BIRZIN, E. T., EARY, C. H., SCHAEFFER, J. M. \& SHOOP, W. L. (1994). Invermectin binding sites in sensitive and resistant Haemonchus contortus. Fournal of Parasitology 80, 493-497.

Roos, M. H. (1990). The molecular nature of benzimidazole resistance in helminths. Parasitology Today 6, 125-127.

RoOs, M. H., BOERSEMA, J. H., BORGSTEEDE, F. H. M., CORnelissen, J., TAYlor, M. \& RUITENBERG, E. J. (1990). Molecular analysis of selection for benzimidazole resistance in the sheep parasite Haemonchus contortus. Molecular and Biochemical Parasitology 43, 77-88.

Roos, M. H. \& Boersema, J. H. (1991). Comparison of 4 benzimidazole susceptible and 9 resistant Haemonchus contortus populations by restriction fragment length polymorphism. In Resistance of Parasites to Antiparasitic Drugs. (ed. Boray, J. C., Martin, P. J. \& Roush, R. T.), pp. 165-171. Rahway, NJ, U.S.A. MSD Agvet.

RoOs, M. H., KWA, M. S. G. \& GRANT, W. N. (1995). New genetic and practical implications of selection for anthelmintic resistance in parasitic nematodes. Parasitology Today 11, 148-150.

Roush, R. T. (1993). Occurrence, genetics and management of insecticide resistance. Parasitology Today 9, 174-179.

SACKET, D. L. \& VERMA, J. K. (1993). Molecular mechanisms of colchicine action: induced local unfolding of $\beta$-tubulin. Biochemistry 32, 13560-13565.

SCHAEFFER, J. M. \& HAINES, H. W. (1989). Avermectin binding in Caenorhabditis elegans: a two-state model for the avermectin site. Biochemical Pharmacology 38, 2329-2338.

SCHIBLER, M. J. \& HUANG, B. (1991). The colR4 and col $\times 15 \beta$-tubulin mutations in Chlamydomonas reinhardtii confer altered sensitivities to microtubule inhibitors and herbicides by enhancing microtubule stability. Fournal of Cell Biology, 113, 605-614.

SCHINKEL, A. H., SMit, J. J., VAN TELlingen, O., BEIJNEN, J. H., WAgENaAR, E., VAN DEEMTer, L., MOL, C. A., VAlK, M. A., ROBANUS-MAANDAG, E. C., TE RIELE, H. P. \& BORST, P. (1994). Disruption of the mouse mdr1a Pglycoprotein gene leads to a deficiency in the blood-brain barrier and to increased sensitivity to drugs. Cell 77, 491-502.

SHOOP, w. L. (1993). Ivermectin resistance. Parasitology Today 9, 154-159.

SMith, G. (1990). A mathematical model for the evolution of anthelmintic resistance in a direct life cycle nematode parasite. International fournal for Parasitology 20, 913-921.

SMith, N. C. (1992). Concepts and strategies for antiparasite immunoprophylaxis and therapy. International Fournal for Parasitology 22, 1047-1082. 
STEAR, M. J. \& MURRAY, M. (1994). Genetic resistance to parasitic disease: particularly of resistance in ruminants to gastrointestinal nematodes. Veterinary Parasitology 54, 161-167.

STEAR, M. J., BAIRDEN, K., BiSHOP, S. C., BUITKAMP, J., EPPlen, J. T., GOSTOMSKI, D., MCKellar, Q. A., SCHWAigER, F.-W. \& WALlace, D. s. (1996). An ovine lymphocyte antigen is associated with reduced fecal egg counts in four-month-old lambs following natural, predominantly Ostertagia circumcincta infection. International Fournal for Parasitology 26, 423-428.

STERNlicht, H., YAFFE, M. B. \& FARR, G. W. (1987). A model of the nucleotide-binding site in tubulin. FEBS Letters 214, 226-235.

TDR (1992). Praziquantel shows unexpected failure in recent schistosomiasis outbreak. TDR News 41, 2-3.

THomas, J. H., NeFF, N. F. \& Botstein, D. (1985).

Isolation and characterization of mutations in the beta-tubulin gene Saccharomyces cerevisiae. Genetics 112, 715-734.

UPPUluRi, S., KNIPLING, L., SACKETT, D. L. \& WOLFF, J. (1993). Localization of the colchicine-binding site of tubulin. Proceedings of the National Academy of Sciences, USA 90, 11598-11602.

WALLER, P. J. (1994). The development of anthelmintic resistance in ruminant livestock. Acta Tropica 55, $233-243$

WALler, P. J., ECHEVARRIA, F., EDDi, C., MACIEL, S., NARI, A. \& HANSEN, J. W. (1996). The prevalence of anthelmintic resistance in nematode parasites of sheep in Southern Latin America: general overview. Veterinary Parasitology 62, 181-187.

WAtson, T. G., Hosking, B. C. \& HURFord, A. P. (1992). Breed variation in expression of faecal nematode egg count. Proceedings of the New Zealand Society of Animal Production 52, 69-71.

Wiley, L. J., Weiss, A. S., SANGSTER, N. C. \& LI, Q. (1997). Cloning and sequence analysis of the candidate nicotinic acetylcholine receptor alpha subunit gene from Trichostrongylus colubriformis. Gene (in press). woolaston, R. R., ElWin, R. L. \& BARger, I. A. (1972). No adaptation of Haemonchus contortus to genetically resistant sheep. International Fournal for Parasitology 22, 377-380. 